BIBECHANA

A Multidisciplinary Journal of Science, Technology and Mathematics

ISSN 2091-0762 (online)

Journal homepage: http://nepjol.info/index.php/BIBICHANA
BIBECHANA
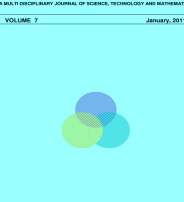

\title{
Free energy of mixing and activity of indium-tin alloy
}

\author{
I.S. Jha ${ }^{a}$, Arun K. Khan ${ }^{\text {b* }}$, B.C. Kumar ${ }^{\mathrm{c}}$ \\ ${ }^{a}$ Dept. of Physics, M.M.A.M. Campus (Tribhuvan University), Biratnagar, Nepal \\ ${ }^{\mathrm{b}}$ Dept. of Physics, R.M. College (B.N. Mandal University), Saharsa, Bihar, India \\ ${ }^{\mathrm{c}}$ University Department of Physics ,T.M. Bhagalpur University, Bhagalpur, Bihar, India \\ Article History: Received 10 October 2010; Revised 5 November 2010; Accepted 12 November 2010
}

\section{Abstract}

Flory's model has been used to calculate the free energy of mixing and activity of In in InSn liquid alloy at $700 \mathrm{~K}$. The values of these thermodynamic parameters obtained from this model are compared with corresponding experimental values. The computed values are in reasonable agreement with the observed values.

\section{Keywords: Flory's model; Activity; Indium-tin alloy}

\section{Introduction}

The indium-tin alloys have been attracting considerable attention due to their several uses. Primary applications of indium-tin alloys include bearing assembly, ballast, casting, step soldering, and radiation shielding. In this paper, we intend to study the thermodynamic properties of indium-tin alloys in molten state at $700 \mathrm{~K}$ on the basis of Flory's model [1]. The thermodynamic mixing properties of liquid alloys are important for understanding process metallurgy and material preparation of metal alloy. The liquidus lines of InSn alloys [2] reveal that the constituent species form complexes at one or more stoichiometric composition. The assumptions of complex formation have been used by several researchers [3-10] to study the mixing properties of alloys in liquid state.

The theoretical background of Flory's model is presented in section 2. Section 3 gives the result and discussion of the work and conclusion of the work is given in section 4 .

\section{Flory's Model}

Considering $\mathrm{Nc}$ mole of $\mathrm{In}$ atoms and $\mathrm{N}(1-\mathrm{c})$ mole of $\mathrm{Sn}$ atoms mixed in molten state,Flory's expression for free energy of mixing of a binary mixture is given by[1]

\footnotetext{
* Corresponding author: Dr. Arun K. Khan, Dept. of Physics, R.M. College (B.N. Mandal University), Saharsa, Bihar, India, Email: arunkumarkhan@gmail.com
} 


$$
\mathrm{G}_{\mathrm{M}}=\mathrm{RT}\left[\mathrm{c} \ln \mathrm{c}+(1-\mathrm{c}) \ln (1-\mathrm{c})+\mathrm{c} \ln (1-\beta)-\ln (1-\beta \mathrm{c})+\omega \mathrm{c} \frac{1-\mathrm{c}}{1-\beta \mathrm{c}}\right.
$$

where $\beta=1-\frac{\left(\mathrm{V}_{\mathrm{In}}\right)_{0}}{\left(\mathrm{~V}_{\mathrm{Sn}}\right)_{0}},\left(\mathrm{~V}_{\mathrm{In}}\right)_{0}$ and $\left(\mathrm{V}_{\mathrm{Sn}}\right)_{0}$ being the atomic volumes of In and Sn respectively. The standard thermodynamic relation for activity of In in binary liquid is given by

$$
\mathrm{RT} \ln \mathrm{a}_{\mathrm{Al}}=\mathrm{G}_{\mathrm{M}}+(1-\mathrm{c}) \frac{\partial \mathrm{G}_{\mathrm{M}}}{\partial \mathrm{c}}
$$

Differentiating equation (1) with respect to 'c' and substituting the value of $\frac{\partial G_{M}}{\partial c}$, one gets

$$
\ln \mathrm{a}_{\mathrm{Al}}=\ln \mathrm{c}+\ln (1-\beta)-\ln (1-\beta \mathrm{c})+\frac{\beta(1-\mathrm{c})}{1-\beta \mathrm{c}}+\frac{\omega}{\mathrm{RT}} \frac{(1-\mathrm{c})^{2}}{(1-\beta \mathrm{c})^{2}}
$$

Once the expressions for $G_{M}$ is obtained, other thermodynamic functions follow readily. Heat of mixing and entropy of mixing are related to $G_{M}$ through standard thermodynamic relations

$$
\begin{aligned}
& \mathrm{H}_{\mathrm{M}}=\mathrm{G}_{\mathrm{M}}-\mathrm{T}\left(\frac{\partial \mathrm{G}_{\mathrm{M}}}{\partial \mathrm{T}}\right)_{\mathrm{T}, \mathrm{P}} \\
& \mathrm{S}_{\mathrm{M}}=\frac{\mathrm{H}_{\mathrm{M}}-\mathrm{G}_{\mathrm{M}}}{\mathrm{T}}
\end{aligned}
$$

Differentiating equation (1) with respect to $\mathrm{T}$ and substituting in equation (4), we get

$\mathrm{H}_{\mathrm{M}}=\omega \frac{\mathrm{c}(1-\mathrm{c})}{1-\beta \mathrm{c}}-\mathrm{T} \frac{\mathrm{c}(1-\mathrm{c})}{1-\beta \mathrm{c}} \frac{\partial \omega}{\partial \mathrm{T}}+\mathrm{RT}^{2} \frac{\mathrm{c}(1-\mathrm{c})}{1-\beta \mathrm{c}}\left[\frac{\beta}{1-\beta}-\frac{\mathrm{c}}{1-\beta \mathrm{c}} \frac{\omega}{\mathrm{RT}}\right] \frac{\partial \beta}{\partial \mathrm{T}}$

where $\frac{\partial \beta}{\partial \mathrm{T}}=\left(\alpha_{\mathrm{Sn}}-\alpha_{\text {In }}\right) \frac{\left(\mathrm{V}_{\mathrm{In}}\right)_{0}}{\left(\mathrm{~V}_{\mathrm{Sn}}\right)_{0}}, \alpha_{\text {In }}$ and $\alpha_{\mathrm{Sn}}$ are linear expansivities of indium and tin respectively.

\section{Results and Discussion}

The value of interchange energy $(\omega)$ was determined from the observed data [2] of $G_{M}$ in the concentration range from 0.1 to 0.9 . The best fit value of $\omega$ used in the present work was found to be $-3.65 \mathrm{~kJ} \mathrm{~mol}^{-1}$. The computed values of $\mathrm{G}_{\mathrm{M}}$ obtained from equation (1) are plotted against $\mathrm{c}_{\mathrm{In}}$ (concentration of $\mathrm{In}$ ) in figure 1 along with its observed values at $700 \mathrm{~K}$. The computed and observed values of $\mathrm{G}_{\mathrm{M}}$ are in reasonable agreement in all concentration range. The computed values are in better agreement with the observed values in higher concentration of In. The computed and observed both values are least at equiatomic composition. The computed and observed values of $\mathrm{G}_{\mathrm{M}}$ are displayed in Table 1 .

Activity is a very important thermodynamic function because it is one of the fortune functions which is obtained directly from experiment and it can be used to obtain other thermodynamic functions. The graph between the experimental and theoretical values of $\ln \mathrm{a}_{\text {In }}$ with respect to $c_{I n}$ is shown in figure 2. It is clear from the graph that the matching of theoretical values with experimental values is relatively better in lower concentration range of In, i.e.; in the region $\mathrm{c}_{\mathrm{Al}}<0.5$ than in higher concentration. The computed and observed values of $\ln \mathrm{I}_{\mathrm{In}}$ are displayed in Table 1. 


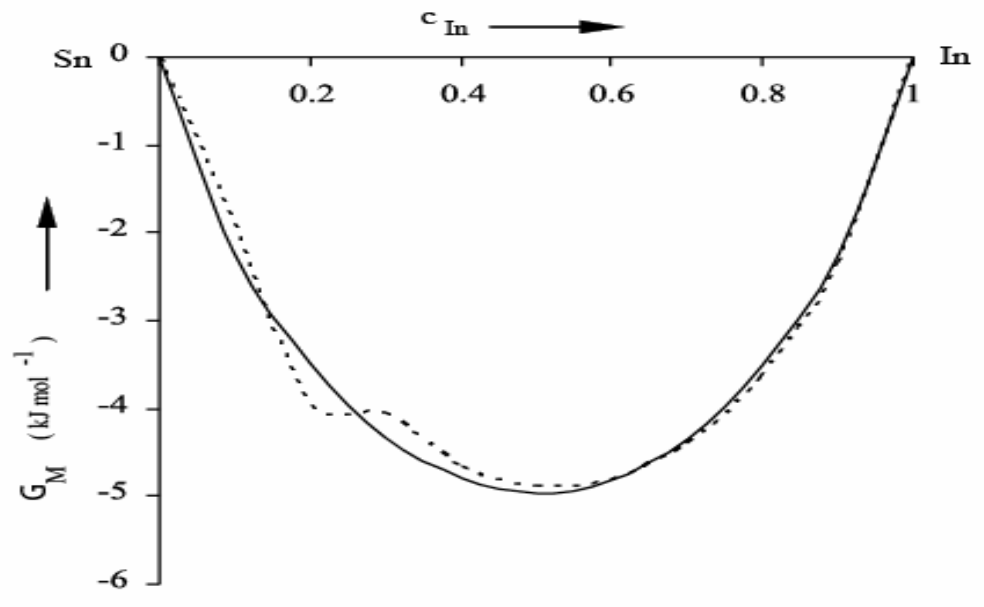

Figure 1: Free energy of mixing $\left(\mathrm{G}_{\mathrm{M}}\right)$ verses concentration of In $\left(\mathrm{c}_{\mathrm{In}}\right)$ of liquid InSn alloy at $700 \mathrm{~K} ;((-)$ theory, $(\ldots \ldots \ldots \ldots)$ experiment [2].

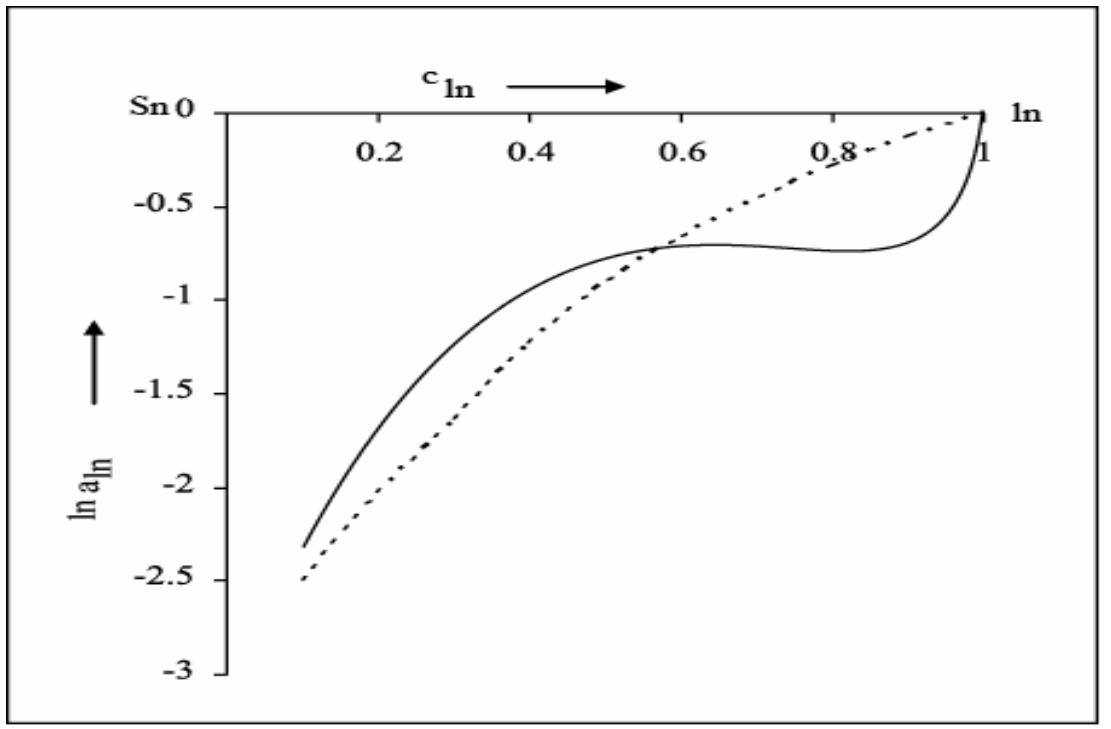

Figure 2: Activity (lna) versus $\mathrm{c}_{\text {In }}$ (concentration of $\mathrm{Al}$ ) in the liquid InSn solution (1073K); (-) theory, (..........) experiment [2].

\section{Conclusion}

We have calculated free energy of mixing and activity of In in In-Sn alloys in molten state. Both of these parameters computed from Flory's model were found to be in 
rescannable agreement with corresponding observed values. The interaction energy was found to be temperature dependent.

Table 1

\begin{tabular}{|c|c|c|c|c|}
\hline \multirow{2}{*}{$\mathrm{c}_{\text {In }}$} & \multicolumn{2}{|c|}{$\mathbf{G}_{\mathbf{M}}\left(\mathbf{k J ~ m o l}^{\mathbf{- 1}}\right)$} & \multicolumn{2}{c|}{ Ina $_{\text {In }}$} \\
\cline { 2 - 5 } & Theoretical & $\begin{array}{c}\text { Experimental }_{[\mathbf{2}]} \\
\end{array}$ & Theoretical & $\begin{array}{c}\text { Experimental } \\
\text { [2] }\end{array}$ \\
\hline 0.1 & -2.221 & -1.902 & -2.313 & -2.501 \\
\hline 0.2 & -3.500 & 3.967 & -1.635 & -2.032 \\
\hline 0.3 & -4.329 & -4.067 & -1.262 & -1.635 \\
\hline 0.4 & -4.805 & -4.669 & -1.024 & -1.234 \\
\hline 0.5 & -4.963 & -4.903 & -0.856 & -0.896 \\
\hline 0.6 & -4.812 & -4.815 & -0.746 & -0.664 \\
\hline 0.7 & -4.341 & -4.410 & -0.681 & -0.460 \\
\hline 0.8 & -3.513 & -3.628 & -0.650 & -0.279 \\
\hline 0.9 & -2.231 & -2.341 & -0.648 & -0.123 \\
\hline
\end{tabular}

\section{References}

[1] P.J. Flory, J. Chem.Phys. Liq. All., 10(1942)51.

[2] R. Hultgren, P. D Desai, D.T Hawkins, M. Gleser and K.K. Kelley, Selected values of the Thermodynamic Properties of Binary Alloys (Metals Park, Ohio: American Society for Metals, (1973).

[3] D. Adhikari, I. S. Jha and B. P. Singh, Phil. Mag., 90 (2010) 2687.

[4] D. Adhikari , I.S. Jha , B.P. Singh, Physica B, 405(2010) 1861.

[5] R.N. Singh and L.C. Prasad, Phys. Chem. Liquid, 22(1990)1.

[6] A.S. Jordan, Metall. Trans., 1 (1970) 239.

[7] D. Adhikari, B.P. Singh, I.S. Jha and B.K. Singh, J. Mol. Liqs., 156 (2010) 155.

[8] B.P. Singh, D. Adhikari and I.S. Jha, J. Non-Crystalline Solids, 356(2010) 1730.

[9] A.B. Bhatia and N.H. March, J. Phys.F:Met. Phys., 5(1975) 1100.

[10] S. Lele and P. Ramchandrarao, Metall. Trans., 12 B (1981) 659. 